\title{
Animal models of intellectual disability: towards a translational approach
}

\author{
Carla A. Scorza,' Esper A. Cavalheiro,,II \\ 'Disciplina de Neurologia Experimental. Universidade Federal de São Paulo/Escola Paulista de Medicina. (UNIFESP/EPM). São Paulo, Brazil. "APAE - São \\ Paulo, Brazil.
}

Intellectual disability is a prevalent form of cognitive impairment, affecting $2-3 \%$ of the general population. It is a daunting societal problem characterized by significant limitations both in intellectual functioning and in adaptive behavior as expressed in conceptual, social and practical adaptive skills. Intellectual disability is a clinically important disorder for which the etiology and pathogenesis are still poorly understood. Moreover, although tremendous progress has been made, pharmacological intervention is still currently non-existent and therapeutic strategies remain limited. Studies in humans have a very limited capacity to explain basic mechanisms of this condition. In this sense, animal models have been invaluable in intellectual disability investigation. Certainly, a great deal of the knowledge that has improved our understanding of several pathologies has derived from appropriate animal models. Moreover, to improve human health, scientific discoveries must be translated into practical applications. Translational research specifically aims at taking basic scientific discoveries and best practices to benefit the lives of people in our communities. In this context, the challenge that basic science research needs to meet is to make use of a comparative approach to benefit the most from what each animal model can tell us. Intellectual disability results from many different genetic and environmental insults. Taken together, the present review will describe several animal models of potential intellectual disability risk factors.

KEYWORDS: Cognitive deficit; Down syndrome; Rett syndrome; Fragile X; Inborn errors metabolism.

Scorza CA, Cavalheiro EA. Animal models of intellectual disability: towards a translational approach. Clinics. 2011;66(S1):55-63.

Received for publication on January 18, 2011; Accepted for publication on January 25, 2011

E-mail: carlascorza.nexp@epm.br

Tel.: 551155764508

Fax: 551155739304

\section{INTRODUCTION}

Intellectual disability (ID) is a prevalent form of cognitive impairment affecting $2-3 \%$ of the population in the industrialized world. ${ }^{1}$ ID is characterized by significant limitations both in intellectual functioning and in adaptive behavior as expressed in conceptual, social and practical adaptive skills. Moreover, this disability originates before age $18 .^{2}$ ID is accepted if the intelligence quotient (IQ) is lower than 70 and is considered borderline from 70 to $85 .{ }^{3,4}$ However, a multidimensional framework for understanding ID depicts how human functioning and the manifestation of ID involve the dynamic, reciprocal engagement among intellectual ability, adaptive behavior, health, participation, context and individualized supports. ${ }^{2}$ ID is a condition of great concern for public health and society. The frequency of ID-related cognitive dysfunction is alarming, considering that pharmacological intervention is currently non-existent. ${ }^{5}$ In this context, ID is one of the more important topics in medical science. It has a complex etiology, with an intricate interplay of genetic and environmental factors, but the causal mechanisms are not understood. ID is one of the few clinically important disorders for which the etiopathogenesis is still poorly understood. In this sense, in order to

Copyright (c) 2011 CLINICS - This is an Open Access article distributed under the terms of the Creative Commons Attribution Non-Commercial License (http:// creativecommons.org/licenses/by-nc/3.0/) which permits unrestricted noncommercial use, distribution, and reproduction in any medium, provided the original work is properly cited. improve human health, scientific discoveries must be translated into practical applications. Such discoveries typically begin at "the bench" with basic research and then progress to the clinical level, or the patients "bedside". Scientists are increasingly aware that this bench-to-bedside approach to translational research is really a two-way street. ${ }^{6}$ Scientists provide clinicians with new tools for use with patients and for assessment of their impact, and clinical researchers make novel observations about the nature and progression of a condition, which often stimulates basic investigation. ${ }^{6}$ This is the first area of translational research called "bench-to-bedside and back". The second area concerns research aimed at enhancing the adoption of best practices in the community. As an example, improvements in medical intervention for people with Down syndrome (DS) have led to a substantial increase in their longevity, with the estimated life expectancy in developed countries increasing from an average of 12 years in the 1940s to an average of 57.8 years for women and 61.1 years for men., 7 in this sense, animal models have been invaluable in ID research, since studies in humans have a very limited capacity to explain basic mechanisms of disease. Animal models facilitate the developmental analysis of the pathogenesis of abnormalities, particularly during crucial stages of organogenesis. Even if appropriate tissues were available in humans, it would be impossible to carry out any investigations other than static biochemical or morphological examinations. Consequently, a great deal of the knowledge that has improved our understanding of several pathologies has derived from appropriate animal 
models. ${ }^{9}$ This is certainly the case of pathologies associated with ID. Arguably the single most essential element in animal-based research, identifying and selecting the most appropriate animal model, is also the most challenging. Different species have species-specific behavioral repertoires shaped by their evolutionary history. ${ }^{10}$ The evolutionary process, by definition, actually refers to the vast differences that exist between species, and even between cells within a given species. Thus, modeling of human-like symptoms in animals should be based primarily on an expectation of functional similarity of the displayed behavioral strategy, rather than on one of behavior equivalency. ${ }^{11}$ The crucial point is not whether a mouse, for example, would show a given cognitive impairment, but, rather, how a cognitive impairment would manifest itself in this mouse. ${ }^{1}$ The challenge that basic science research needs to meet is to make use of a comparative approach to benefit the most from what each model can tell us. ${ }^{12}$ Anyhow, the use of animal models of ID are critical for determining the basic mechanisms, the neurobiological substrates and the neural basis of cognitive function as well as for testing the efficacy of potential therapeutic drugs and the neurotoxicity of environmental contaminants and drugs of abuse, among others.

The causes of ID are extremely heterogeneous and although a cause for ID has been diagnosed in about half of cases, it has been estimated that half of all cases are due to environmental factors and half to genetic factors. ${ }^{13}$ Environmental factors include prenatal exposure of the fetus to toxic substances (e.g., alcohol, drugs), environmental contaminants, radiation, infection, malnutrition, illness of the mother (e.g., exposure to toxoplasmosis, cytomegalovirus and rubella), etc. In addition, multiple problems, during or after birth, may also culminate in ID. ${ }^{14}$ This review shall describe several animal models of potential ID risk factors. We have organized this review as shown in Table 1.

\section{GENETIC MODELS}

About one-third of all genetic disorders show some neurological involvement, and many of these represent

Table 1 - Animal models.

\begin{tabular}{cl}
\hline Genetic models & Down syndrome \\
& Fragile X syndrome \\
& Rett syndrome \\
Inborn errors of metabolism & Neurotoxic insults \\
Environmental & Selective neurotoxin-induced model \\
conditions & Neurotoxic treatment of the \\
& developing fetus \\
& Environmental neurotoxic insults \\
& Maternal exposure to infections \\
& Congenital toxoplasmosis \\
& Congenital cytomegalovirus \\
& Congenial rubella \\
Maternal exposure to teratogenics \\
development & Fetal alcohol syndrome \\
& Malnutrition \\
Age-related changes & Pypoxic-ischemic insult \\
& Status epilepticus \\
& Down syndrome Ts65Dn mouse \\
& Transgenic mouse models of amyloid \\
& deposition \\
& Cholinergic receptor knockout mice \\
\hline
\end{tabular}

neurodegenerative diseases of infancy. Genetic or genetically influenced conditions rank among the leading causes of organically based mental retardation. Genetically modified mice are currently the most commonly used approach to investigate the role of a specific genetic alteration and to model pathologies leading to intelligence disability. The mouse is the most widely used laboratory species to provide insights linking specific genes to biological functions. Its wide use is primarily because, among mammals, the mouse is most amenable to genetic manipulation. Furthermore, our extensive knowledge of the genome, physiology and behavior of the mouse makes it possible to interpret the effects of gene manipulations. ${ }^{1}$

\section{Down syndrome}

DS caused by trisomy of human chromosome 21 (HSA21), shows an incidence of about 1 in 733 live births. ${ }^{15}$ DS is characterized by abnormalities in learning, memory and language; some degree of intelligence disability is essentially universal. ${ }^{16}$ Furthermore, individuals with trisomy 21 may show a wide range of pathological features, such as heart disease, sterility, higher incidence of leukemia, immune system perturbations and premature aging. Moreover, they also display muscular hypotonia, deposition of Alzheimer-like plaques and neurofibrillary tangles in the brain in the third decade of life. ${ }^{1,17,18}$ Lejeune et al. ${ }^{19}$ showed that an extra copy of human chromosome 21 (now HSA21) was found in DS. The discovery provided the first evidence for a genetic substrate of intelligence disability. Although DS pathogenesis may be complex, all changes must arise from excess genetic material on HSA21, which encodes 300 known and predicted genes. ${ }^{20}$ Mouse models of TRS21 have been developed using syntenies between HSA21 and MMU16, MMU10 and MMU17. Available mouse models carry extra fragments of MMU16 or of HSA21 that cover all of HSA21 (chimeric HSA21) or MMU16 (Ts16); some carry large parts of MMU16 (Ts65Dn, Ts1Cje, Ms1Cje), whereas others have reduced contiguous fragments covering the D21S17-ETS2 region or single transfected genes. ${ }^{21}$ Among these, Ts65Dn and Ts1Cje mouse models have been extensively used to study DS neurobiological phenotypes. The Ts65Dn mouse, with an extra copy of about 104 mouse genes orthologous to those on HSA21, shows a number of developmental and functional parallels with DS. These include changes in behavior, alterations in the structure of dendritic spines in the cortex and hippocampus, and failed hippocampal long-term potentiation (LTP). ${ }^{22-25}$ Ts1Cje mice, which are trisomic for a shorter but fully overlapping segment of MMU16 (about 81 genes), show similar changes, usually to a somewhat lesser degree. ${ }^{25-29}$ Several other DS mouse models have been developed. ${ }^{1}$ The understanding of the pathogenicity of the extra genomic material in trisomy 21 has accelerated in recent years because of the recent advances in genome sequencing, comparative genome analysis, functional genome exploration and the use of animal models. ${ }^{30}$ Aneuploidy, defined as an abnormal number of copies of a genomic region, is recognized as a common mechanism of human genetic disease, often leading to abnormal gene expression patterns with overor underexpression of specific genes. ${ }^{31}$ Surprisingly, a significant number of human brain cells (both neurons and non-neuronal cells) can be aneuploidy, and the resulting genetic mosaicism is a normal feature of the human central nervous system. ${ }^{32}$ But, what could be 
the mechanisms by which the anatomical, chemical and neurophysiological brain abnormalities underlying ID arise from deregulation of gene expression? Major questions are still unanswered. Genetically modified mouse models have been helping to investigate the contributions of specific gene alterations and gene-environment interactions to the phenotype of several forms of ID.

\section{Fragile $X$ syndrome}

X-linked disorders may explain why males show a 25$35 \%$ higher incidence of mental disabilities than females. It is imperative to gain knowledge of the mechanisms specific to the $\mathrm{X}$-chromosome (e.g., $\mathrm{X}$-inactivation, gene regulation) that may be relevant to understanding some forms of $X$ linked mental retardation. Fragile $X$ syndrome (FXS) is the leading cause of heritable intelligence disability, affecting about 1 in 1400 males and 1 in 2500 females. FXS is caused by a trinucleotide expansion in the fragile $X$ mental retardation 1 gene ( $f m r 1$ ) that prevents the expression of the encoded protein, called fragile $X$ mental retardation protein (FMRP). ${ }^{33}$ The genetic defect is an unstable region of DNA on the $X$ chromosome that becomes highly expanded when transmitted through the maternal lineage. FXS is a common form of mental retardation associated with attention deficit, autistic behavior, hyperactivity and epileptic seizures. ${ }^{34}$ The phenotype of FXS is reproduced in fmr1 knockout (KO) mice that, among others, have regionspecific altered expression of some gamma-aminobutyric acid (GABA) receptor subunits. ${ }^{35,36}$

\section{Rett syndrome}

Rett syndrome (RTT) is an X-linked autism spectrum disorder found almost solely in females. Clinical characteristics include abnormal motor gait, stereotypic hand wringing movements and autistic-like behavior. Affected girls also exhibit speech abnormalities and severe intellectual disability in most cases. ${ }^{37}$ One peculiar aspect of this disorder is that individuals appear normal at birth, then, between 6 and 18 months, they begin to lose some already acquired skills, such as communication, language and motor coordination. ${ }^{1} \mathrm{RTT}$ is caused by mutations in $M E C P 2$, encoding methyl CpGbinding protein 2. Since the discovery of $M E C P 2$ mutations as the genetic cause of RTT in $1999,{ }^{38}$ the understanding of $\mathrm{MeCP} 2$ function has evolved. In past years, researchers have produced mice with genetically altered MeCP2 that displayed some features of Rett in order to characterize the biological, pathological and behavioral features of these mice and have compared them with the human condition. ${ }^{39-41}$ Combined epigenomic approaches of MeCP2 binding, methylation and gene expression have demonstrated that $\mathrm{MeCP} 2$ binds preferentially to intergenic and intronic and sparsely methylated promoters of active genes. ${ }^{42}$ While autism is strongly heritable, most cases of autism are expected to be due to a combination of genetic, environmental and epigenetic factors. As in the case of RTT, genetic disorders on the autism spectrum affecting epigenetic pathways include Angelman, Prader-Willi and 15q duplication syndromes. ${ }^{42}$ Thus, armed with intense research, improved understanding and therapies for RTT, and perhaps a subset of autism cases, are certain to follow.

\section{Inborn errors of metabolism}

Metabolic disorders result from the absence or abnormality of an enzyme or its cofactor, leading to either accumulation or deficiency of a specific metabolite. Optimal outcome for children with inborn errors of metabolism (IEM) depends upon prompt recognition, evaluation and management of these disorders. ${ }^{43}$ Delay in diagnosis may result in acute metabolic decompensation, progressive neurologic injury, or even death. Animal models of metabolic diseases especially focus on the pathophysiology mechanisms due to imbalances in amino acids, mucopolysaccharides, purines, lipids and carbohydrates, or the dysfunction of cellular organelles (e.g., mitochondria, peroxisomes, lysosomes, or Golgi) that contribute to intelligence and developmental disabilities as well as to the development of therapeutic strategies (i.e., genetic or pharmacological) that aid in the diagnosis and clinical management of these IEM disorders. ${ }^{44}$ Specific examples of metabolic disorders associated with intelligence disability include phenylketonuria, Lesch-Nyhan, galactosemia and adrenoleukodystrophy. In the 70s in Brazil, Benjamin Schmidt and colleagues started a project called "A national plan for study and detection of IEM disorders that could lead to mental deficiency". In the sequence, Brazil established the first Newborn Screening Programme for IEM in Latin America for the detection of phenylketonuria and other IEM capable of causing intelligence disability. ${ }^{45,46}$ However, today, the few data available lead to the conclusion that neither newborn screening nor phenylk etonuria treatment centers cover all the Brazilian cases. ${ }^{47}$ In addition, most phenylketonuria patients have to leave their home states to seek better treatment. Moreover, the required specific foods are not readily available and are expensive. New options are being researched, nevertheless, there is much to be done, mainly on food research and production. ${ }^{47}$

\section{ENVIRONMENTAL CONDITIONS}

There are a host of environmental conditions that affect biological risk for intelligence and developmental disabilities, among them are (a) neurotoxic insults, (b) maternal exposure to infections (e.g. toxoplasmosis, cytomegalovirus and rubella), (c) maternal exposure to teratogenics (e.g., alcohol), (d) malnutrition.

\section{Neurotoxic insults}

Selective neurotoxin-induced models. Many individuals with intellectual disability exhibit chronic aberrant behavior that includes hyperactive, stereotyped, aggressive and selfinjurious behaviors (SIBs). ${ }^{48}$ SIB is a severe symptom in Lesch-Nyhan syndrome (LNS), a genetic disorder associated with deficiency of the enzyme hypoxanthine-guanine phosphoribosyltransferase (HPRT). HPRT-deficient mice provided the first demonstration that genetically engineered mice could be produced as models for a specific human disease. $^{49}$ It has been showed that these mice presented reduced dopamine along with microstructural anatomical abnormalities, demonstrating that HPRT deficiency leads to a loss of basal ganglia dopamine through a metabolic process. ${ }^{50,51}$ Unfortunately, the main limitation of these mice is that they do not exhibit some of the more complex aspects of the LNS phenotype, such as the consequences of uric acid overproduction or the neurobehavioral syndrome. As a result, they are of limited value for directly addressing these aspects of the disorder. ${ }^{51}$ In this sense, another animal model has been developed to address the functional significance of dopamine 
loss due to neurobehavioral syndrome. ${ }^{52,53}$ Because the prominent neurobiological deficit in LNS is a loss of dopaminergic neurons, reduction of dopamine 6-hydroxydopamine in rats during their development is proposed as a model of dopamine deficiency in LNS as well as in individuals with ID and SIB, who may have this neurotransmitter deficiency. Accompanying the profound loss of dopamine was an increase in striatal serotonin content. When the neonatally lesioned rats were challenged as adults with systemically administered L-DOPA or with muscimol administration into the substantia nigra reticulata (SNR), SMB was observed, a response not observed in unlesioned rats. Since $\mathrm{D}_{1}$-dopamine antagonist blocked the $\mathrm{SMB}$ response to L-DOPA, it was proposed that $\mathrm{D}_{1}$-dopamine receptors were critical to this behavioral response. ${ }^{52}$

Neurotoxic treatment of the developing fetus. The administration of the alkylating neurotoxin methylazoxymethanol acetate (MAM, $25 \mathrm{mg} / \mathrm{kg} \mathrm{sc}$ ) to pregnant rats on day 14 or 15 of gestation induces, in the offspring, a marked microencephaly. ${ }^{54}$ MAM treatment severely reduces intrinsic neuronal populations including GABAergic and glutamatergic neurons and produces a shrunken cortex relatively hyperinnervated by noradrenergic and cholinergic neurons. ${ }^{55}$ MAM-induced brain and behavioral abnormalities provide an animal model of congenital microencephaly associated with intelligence disability. The MAM offspring showed no increase in mortality, but weighed less than controls. ${ }^{56}$ In addition, MAM-treated rats display a characteristic hyperactivity. This hyperactive state was accompanied by notable impairments in the acquisition of spatial instrumental learning tasks. ${ }^{57}$ At 2 months of age, the MAM offspring showed pronounced deficit in learning a water maze; this deficit was not abated when animals were tested again at 6 months of age, implicating longterm learning impairments. ${ }^{56}$

Environmental neurotoxic insults. Neurotoxicity is a potentially major contributor to the etiology of many types of intelligence and developmental disabilities. For instance, models of developmental risk in neurotoxicology have guided environmental regulation to reduce the likelihood of neurotoxic effects. On the other hand, models of developmental risk for ID aim for prevention and early intervention. ${ }^{58}$ Over the past three decades, researchers have found that remarkably low-level exposure to environmental toxins (e.g., heavy metals, polychlorinated biphenyls (PCBs), pesticides and herbicides, organic solvents, environmental tobacco smoke, radiation and endotoxins) has been linked to intellectual impairments, learning disabilities, behavioral problems, spontaneous abortions, or preterm births. ${ }^{59-62}$ Lead is probably the most-studied environmental contaminant with respect to the effects of developmental exposure on cognition in children or animal models. ${ }^{63}$ PCBs were banned in the 1970 s but their extreme stability allowed them to bioaccumulate over time, such that they remain one of the most prevalent environmental contaminants. In this case, animal research has helped to reveal the differential effects of neurodevelopmental exposure to PCBs in producing significant disruption of tasks that require executive function. As a testament to the usefulness of animal models, recent follow-up studies of several human PCB cohorts have employed domain-specific tests such as the Wisconsin Card Sorting Task ${ }^{64}$ and continuous performance tasks $^{64,65}$ that assess specific aspects of executive control. These recent assessments have yielded results that are strikingly consistent with the findings in animal models, and they highlight the utility of animal models for predicting specific cognitive domains that are likely to be impacted in exposed human populations.

\section{Maternal exposure to infections}

Congenital toxoplasmosis. Different animal models of congenital toxoplasmosis have previously been developed in mice, rats, sheep and guinea pig. ${ }^{66-69}$ The intracellular protozoan Toxoplasma gondii is a widespread opportunistic parasite of humans and animals, and transmission from animals to humans occurs mainly through oocysts excreted in the feces of infected cats, and meat products from farm animals contaminated with viable tissue cysts. ${ }^{70}$ Pregnant women who are infected with $T$. gondii usually remain asymptomatic, although they can still transmit the infection to their fetuses, with severe consequences. Primary infection during pregnancy may result in neonatal death or in severe congenital defects such as hydrocephalus, mental retardation and retinochoroiditis, which may occur at birth or during development. ${ }^{7,71}$ An effective vaccine should protect against both acute and chronic infection. The development of suitable laboratory models is essential for evaluation of the efficacy of the different recombinant subunit vaccine candidates against congenital toxoplasmosis.

Congenital and perinatal infections with cytomegalovirus. These are responsible for considerable short- and long-term morbidity in infants. Cytomegalovirus (CMV) is the most common congenital viral infection in the developed world, occurring in $0.5-2 \%$ of all births and is a common cause of neurodevelopmental injury, including mental retardation and sensorineural hearing loss $(\mathrm{SNHL}){ }^{72}$ Its clinical manifestations range from asymptomatic forms $(90 \%$ of cases) to severe fetal damage and, in rare cases, death due to abortion. Furthermore, $10-15 \%$ of children who are asymptomatic at birth may develop late sequelae after a period of months or even years. ${ }^{73}$ Animal models are imperative for the understanding of the host-virus relationship, which can be exploited to delineate the mechanisms of pathogenesis to develop therapeutic strategies to prevent $\mathrm{CMV}$-associated diseases; however, $\mathrm{CMVs}$ are highly species specific. Consequently, each CMV species is highly adapted to its respective host species and is unable to infect other, even closely related, hosts. ${ }^{74}$ Despite being fascinating from an evolutionary perspective, this restriction prevents studying CMV in experimental animals. Exceptions are severely immunocompromised mice, which might allow partial reconstitution of CMV infection in rodents. ${ }^{74}$

Congenital rubella syndrome. Most of the environmental conditions that affect the biological risk for intelligence and developmental disabilities are preventable. In several cases, we, as a society, have been remarkably successful in preventing their effects. congenital rubella syndrome (CRS) is a case in point. ${ }^{58}$ In 1963-65 there was an epidemic of more than 25000 cases of CRS in the United States. However, since the development of the rubella vaccine in 1969, the incidence has dropped markedly. In 1996 only two cases of CRS were reported in the United States. ${ }^{58,75}$ Although Brazil strives to achieve high immunization coverage through the routine vaccination program and follow-up campaigns, rubella incidence increased in the country between 2006 and 2007. For this reason, in 2008, Brazil launched a major and successful 
national immunization campaign to eliminate rubella and CRS. ${ }^{76}$ The main defects associated with CRS are deafness, eye defects such as cataracts, cardiovascular defects and central nervous system damage, leading to intelligence disability. ${ }^{77}$ It is common to try to study human pathologies by establishing animal models and certainly that was the case for CRS. However, several discrepancies have been found in such studies. Low incidences of cataracts have been reported in the offspring of infected pregnant rats, rabbits and monkeys. In contrast, other studies with pregnant animals (e.g., rats, mice, rabbits, ferrets and monkeys) have not shown these defects. ${ }^{77}$ Moreover, abnormalities of the heart, cerebral blood vessels, and inner ear have been reported in some studies, but incidences are very low and inconsistent. ${ }^{77}$ Taken together, animal models of CRS have not contributed much to the understanding of their pathogenesis. On the other hand, the use of animals as models for microbiological infections has been a fundamental part of infectious disease research. Thus, the use of animal models for a myriad of bacterial and viral diseases has led to the production of vaccines for diseases such as rubella.

\section{Maternal exposure to teratogenics}

Fetal alcohol syndrome. Fetal alcohol syndrome (FAS) and the subsets of individuals with attenuated phenotype subsumed under the umbrella term of fetal alcohol spectrum disorder (FASD) provide clinicians with a challenge. ${ }^{78}$ Individuals with FASD have a higher incidence of impairments in social adaptive and executive function, and a higher degree of psychopathology than the general population. The diagnosis of FAS is based on the occurrence of the following main symptoms: growth deficiency, dysmorphic characteristics, central nervous system dysfunctions, intelligence disability, delays in sensorimotor development, attention deficit, memory disorders, hyperactivity and sleep disturbances. ${ }^{57}$ Animal models of FASD have been used to demonstrate the specificity of the teratogenic effects of alcohol and some of the underlying changes in the central nervous system and to explore ways to ameliorate the effects of alcohol. ${ }^{79}$ The effects of acute alcohol exposure on specific days during the embryonic period have been studied fairly extensively in rodents. Exposure on gestation days 7 and 8 in mice has shown to result in craniofacial defects similar to those seen is FAS (e.g., micrognathia, low-set ears, short philtrum, cleft palate, cleft lip), ${ }^{80}$ as well and brain anomalies (e.g., microcephaly, exencephaly, deficiencies in cerebral hemispheres, striatum, olfactory bulbs, limbic structures, corpus callosum, lateral ventricles). ${ }^{81}$ In addition, ocular defects (anophthalmia, microphthalmia, corneal and lens anomalies) were associated with acute alcohol exposure on gestation day $7 .^{82,83}$ Research has indicated that environmental enrichment and voluntary exercise have been shown to ameliorate some of the effects of alcohol during development, but the roles of enhanced social interactions in the case of enrichment, social housing and voluntary exercise need to be more fully delineated. ${ }^{79}$ In addition, findings of alterations in maternal care of the alcohol-exposed offspring, epigenetic effects and their relationship to social behavior in animal models of FAS are a fruitful area of research. ${ }^{79}$

\section{Malnutrition}

Malnutrition is a worldwide health problem; it exists in many forms, affects the developing and mature nervous system, and has acute and chronic health implications.
Malnutrition in children has particularly severe consequences for growth, development, health and well-being, both on a short- and on a long-term basis, including a high risk for ID. ${ }^{84}$ Malnutrition was associated with $54 \%$ of deaths in children in developing countries. ${ }^{85}$ In developed countries, childhood malnutrition occurs mostly secondary to chronic diseases, and it may be aggravated by frequent hospital stays and diagnostic examinations. ${ }^{86}$ Most concepts basic to nutritional investigations have been derived from animal studies. One distinct characteristic of the research on protein energy malnutrition and child development is the selective focus on learning and intelligence. Historically, work in animals on the functional consequences of energy and protein deprivation has moved in two directions: one approach aims the understanding of the developmental changes in the anatomy and biochemistry of the brain in experimental animals, while the other one describes the compromise of behavioral competence. ${ }^{87}$

\section{BRAIN LESIONS AT EARLY DEVELOPMENT}

\section{Hypoxic-ischemic insult}

Despite major advances in monitoring technology and knowledge of fetal and neonatal pathologies, hypoxicischemic encephalopathy (HIE) remains a serious condition that causes significant mortality and long-term morbidity. HIE represents a common cause of chronic handicapping conditions such as cerebral palsy, intelligence disability, learning disability and epilepsy. ${ }^{88}$ In an established model of perinatal HIE brain damage, neonatal animals undergo carotid artery ligation and hypoxia. ${ }^{89}$ Animal models have long been established in the study of neonatal HIE and have been found suitable for acute and chronic studies. Multiple therapeutic trials are currently being conducted in animal models to explore various methods of interventional therapy against HIE-induced brain damage, with recent breakthroughs in the demonstration of a neuroprotective effect of some anti-apoptosis agents and other methods, such as hypothermia. ${ }^{90-92}$ Premature births result in an increased likelihood of intelligence disability. Premature infants are at high risk of intracranial hemorrhage, asphyxia and the damaging effects of subsequent HIE. ${ }^{93-95}$ Existing models of pediatric hypoxic-ischemic brain damage studied the effects of glutamate in the postnatal day 7 rat, which is considered analogous to the newborn human. ${ }^{96}$ In this sense, the newborn rat is considered analogous to the late gestational human. In order to model preterm hypoxic ischemic brain damage events, it has been proposed that treatment of newborn rats with muscimol mimics the initiation of a cell death cascade induced by hypoxia or injury in premature infants and is analogous to the accepted method of glutamate administration to the week-old rat pup to model the newborn human. ${ }^{97}$ Following this line of evidence, Nuñez et al. ${ }^{97}$ proposed that the excitatory drive through the $\mathrm{GABA}_{\mathrm{A}}$ receptor in early development may be an important contributor to some forms of brain damage in premature infants. Furthermore, they also investigated the effect of postnatal day 0 and 1 muscimol treatment by performing a pre-weaning version of the water maze and an open field maze on postnatal day 21, two tasks that are sensitive to hippocampal function. Taken together, it has been proposed that rats exposed to excessive $\mathrm{GABA}_{\mathrm{A}}$ receptor activation over the first 2 days of postnatal life serve as a model for pre-term infant brain damage. ${ }^{98}$ 


\section{Pediatric head trauma}

Trauma to the developing brain still represents a poorly explored field. Perinatal head trauma can lead to intellectual disability among other severe consequences. Head trauma is the leading cause of death and disability in the pediatric population. ${ }^{99}$ In efforts to model pediatric head trauma, Bittigau et al. ${ }^{99}$ have developed a model for head trauma in infant rats in an attempt to study mechanisms of neurodegeneration in the developing brain. In order to morphologically characterize two distinct types of brain damage they have demonstrated that, in the developing rat brain, apoptosis and not excitotoxicity determined neuropathologic outcome following head trauma. In this sense, they suggested that radical scavengers and tumor necrosis factor inhibitors may be useful in the treatment of pediatric head trauma. ${ }^{100}$ In this line of evidence, trauma triggers both excitotoxic and apoptotic neurodegeneration in the developing rat brain. Excitotoxic neurodegeneration develops and subsides rapidly (within hours), whereas apoptotic cell death occurs in a delayed fashion over several days following the initial traumatic insult. ${ }^{99}$

\section{Status epilepticus}

Status epilepticus (SE) is a medical and neurologic emergency. In Brazil, the annual occurrence of SE is about 90000 cases. ${ }^{101}$ Thus, increased awareness of presentation, etiologies and treatment of SE is essential in the practice of critical care medicine. Elegant animal studies in the 1970s and 1980s revealed significant damage to the brain after $30 \mathrm{~min}$ of seizure activity, even with control of blood pressure, respiration and body temperature. ${ }^{102,103}$ Damage to brain tissues resulting from recurrent convulsive seizures induced by chemicals such as pilocarpine ${ }^{104}$ or kainic acid treatment ${ }^{105}$ may also constitute models of intellectual disability. These animal models are useful for the study of SE-induced epileptogenesis and neurological sequelae, especially during early brain development. Our laboratory group showed several permanent abnormalities in rats subjected to multiple SE induced by pilocarpine (ip) during early development (7-9 days old). In adulthood, these animals presented frequent episodes of continuous complex spiking activity and high-voltage ictal discharges and evidence of severe cognitive deficits. ${ }^{104}$ SE may result in important plastic changes in critical periods of brain maturation leading to long-lasting epileptogenesis, as manifested by electrographic epileptiform discharges, behavioral deficits and in vitro hyperexcitability of hippocampal networks.

\section{AGE-RELATED CHANGES}

\section{Down syndrome Ts65Dn mouse}

As described above, DS results from trisomy of all or part of human chromosome 21, which generally accounts for triplication of at least 100 genes. Among these is the gene encoding amyloid protein precursor (APP), as well as genes that upregulate APP expression. ${ }^{106}$ Beta-amyloid is overproduced in DS individuals throughout life. ${ }^{107}$ The partial trisomy 16 (Ts65Dn) mouse is considered the gold standard of DS mouse models. Ts65Dn mice have an extra copy of the distal aspect of mouse chromosome 16, a segment homologous to human chromosome 21 that contains much of the genetic material responsible for the DS phenotype, including three copies of APP. ${ }^{108}$ Ts65Dn mice show developmental delay during the postnatal period as well as abnormal behaviors in both young and adult animals that may be analogous to mental retardation. Additionally, by 6 months of age, Ts65Dn mice begin progressive, age-related decline in choline acetyltransferase levels and cognitive function, features common to adult DS and Alzheimer patients. ${ }^{109}$ Moreover, although the Ts65Dn brain is normal on gross examination, there is age-related degeneration of septohippocampal cholinergic neurons and astrocytic hypertrophy, markers of Alzheimer disease pathology that are also present in elderly DS individuals. ${ }^{110}$ These findings suggest that Ts65Dn mice may be useful to study certain developmental and degenerative abnormalities in the DS brain.

Cognitive impairment in transgenic mouse models of amyloid deposition.

The identification of the $\mathrm{A} \beta$ peptide as a major component of amyloid deposited in brain vessels and subsequently of parenchymal plaques in the brains of Alzheimer's subjects ${ }^{111}$ led to a focus on this molecule as a key element in the pathophysiology of Alzheimer disease. Subsequent work found that some mutations causing the disease occurred in the amyloid precursor protein (APP) that is processed, in some circumstances, into the A $\beta$ peptide. ${ }^{112}$ As for other disorders, development of animal models to understand amyloid pathology became an important research goal. Hsiao et al. ${ }^{113}$ were the first to demonstrate that APP transgenic mice had both amyloid deposits and memory deficit. They demonstrated deficits in a reference memory version of the open-pool water maze,${ }^{114}$ with the deficits first appearing at an age when the amyloid plaques started to appear (10-11 months). APP transgenic mice are a very good model of amyloid deposition. The patterns of deposition, regional distribution and even the anatomical localization of the short and long variants mimic the human disease. The APP mouse phenotype also consistently includes progressive memory impairment. This phenotype appears to be due to $A \beta$ accumulation and not overexpression of APP, as the BACE1-null background, which overproduces APP but not A $\beta$, rescues the memory phenotype ${ }^{115}$ In addition, a number of manipulations, most notably immunotherapies, have been found to regulate the memory phenotype. However, the mechanisms mediating memory deficiencies are not clear.

\section{Cholinergic receptor knockout mice}

The essential involvement of the cholinergic system in both preclinical and clinical aspects of cognition processes has been extensively proposed. The literature shows that currently approved drugs for the treatment of Alzheimer disease are cholinesterase inhibitors, which exert their efficacy apparently through stimulation of both muscarinic acetylcholine receptors (mAChRs) and nicotinic acetylcholine receptors (nAChRs). ${ }^{116,117}$ Transgenic and KO mouse models are particularly useful for studies of complex neurobiological problems such as $\mathrm{mAChR} \mathrm{KO}$ mice, nAChR KO mice as well as acetylcholinesterase (AChE) $\mathrm{KO}$ mice. To illustrate, in the AChE -/- mice, the $\mathrm{M}(1), \mathrm{M}(2)$ and $\mathrm{M}(4) \mathrm{mAChRs}$ showed a striking $50-80 \%$ decreased expression in brain regions associated with memory. ${ }^{118}$ In addition, a large body of evidence has demonstrated that nicotine has a clinical utility for cognitive enhancement. However, for most diseases in the central nervous system, the coexistence of malfunctions in multiple subtypes of the 
same receptor or in multiple neurotransmitters typically contribute to a complex phenotype such as cognition. ${ }^{117}$ Therefore, cholinergic-based strategies will likely remain valid as one approach to understanding and to rational drug development for the treatment of Alzheimer disease and other forms of dementia and cognitive impairment.

\section{CONCLUSION}

ID is a lifelong condition and it is a daunting societal problem. ID results from many different genetic and environmental insults. Although tremendous progress has been made, pharmacological intervention is currently still non-existent and therapeutic strategies remain limited. However, similarities across the spectrum of ID-related disorders argue that common mechanisms underlie the manifestation of learning and memory deficits in intellectual disabled individuals. Interestingly, many of the histological features noted in the brains of subjects with DS parallel phenotypes that have been found in the brains of individuals with other classes of ID, such as genetic disorders, including inborn errors of metabolism and nongenetic insults. ${ }^{5}$ Nevertheless, ID is a clinically important disorder for which the etiology and pathogenesis are still poorly understood. The past decades have seen extraordinary progress in understanding, preventing and treating the behavioral and cognitive deficits associated with ID. Doubtless, animal models have been invaluable in ID investigation, and continued progress will require programmatic research. Progress in understanding and treating ID will require translational research efforts. Translation research means the transformation of knowledge through successive fields of research from basic scientific discovery to public health impact.

\section{REFERENCES}

1. Branchi I, Bichler Z, Berger-Sweeney J, Ricceri L. Animal models of mental retardation: from gene to cognitive function. Neuroscience and Behavioral Rev. 2003;27:141-53, doi: 10.1016/S0149-7634(03)00016-2.

2. AAIDD. American Association on Intellectual and Developmental Disabilities. Intellectual Disability: definition, classification, and systems of supports. The AAIDD Ad Hoc Committee on Terminology and Classification. 11th ed. Washington, DC: AAIDD; 2010.

3. Luckasson R, Coulter DL, Polloway EA, Reiss S, Schalock RL, Snell ME, et al. In:Mental Retardation: Definition, Classification, and Systems of Supports. 9th ed. Washington, DC: American Association on Mental Retardation; 1992.

4. Shogren KA, Turnbull HR. Public policy and outcomes for persons with intellectual disability: extending and expanding the public policy framework of AAIDD's 11th Edition of Intellectual Disability: Definition, Classification, and Systems of Supports. Intellect Dev Disabil. 2010;48:375-86, doi: 10.1352/1934-9556-48.5.375.

5. Fernandez F, Garner CC. Over-inhibition: a model for developmental intellectual disability. Trends Neurosci. 2007;30:497-503, doi: 10.1016/j. tins.2007.07.005.

6. NIH Common Fund Translational Research Overview (2006). Available from: http://nihroadmap.nih.gov

7. Bittles AH, Bower C, Hussain R, Glasson EJ. The four ages of Down syndrome. Eur J Public Health. 2007;17:221-5, doi: 10.1093/eurpub/ ckl103.

8. Lott IT, Dierssen M. Cognitive deficits and associated neurological complications in individuals with Down's syndrome. Lancet. 2010;9:623-33, doi: 10.1016/S1474-4422(10)70112-5.

9. Curia G, Longo D, Biagini G, Jones RSG, Avoli M. The pilocarpine model of temporal lobe epilepsy. J Neurosci Methods. 2008;172:143-57, doi: 10.1016/j.jneumeth.2008.04.019.

10. Darwin C. The Expression of Emotions in Man and Animals. Oxford: Oxford University Press; 1872.

11. Bucan M, Abel T. The mouse: genetics meets behaviour. Nat Rev Genet Rev. 2002;3:114-23, doi: 10.1038/nrg728.

12. Cirulli F, Francia N, Berry A, Aloe L, Alleva E, Suomi SJ. Early life stress as a risk factor for mental health: role of neurotrophins from rodents to non-human primates. Neurosci Biobehav Rev. 2009;33:573-85, doi: 10. 1016/j.neubiorev.2008.09.001.

13. Curry CJ, Stevenson RE, Aughton D, Byrne J, Carey JC, Cassidy S, et al. Evaluation of mental retardation: recommendations of a consensus conference. Am J Med Genet. 1997;72:468-77, doi: 10.1002/(SICI)10968628(19971112)72:4<468::AID-AJMG18>3.0.CO;2-P.

14. Winnepenninckx B, Rooms L, Kooy RF. Mental retardation: a review of the genetic causes. Br J of Dev Dis. 2003;49:29-44.

15. Canfield MA, Honein MA, Yuskiv N, Xing J, Mai CT, Collins JS, et al National estimates and race/ethnic-specific variation of selected birth defects in the United States, 1999-2001. Birth Defects Res A Clin Mol Teratol. 2006;76:747-56, doi: 10.1002/bdra.20294.

16. Nelson L, Johnson JK, Freedman M, Lott I, Groot J, Chang M, et al. Learning and memory as a function of age in Down syndrome: a study using animal-based tasks. Prog Neuropsychopharmacol Biol Psych. 2005;29:443-53, doi: 10.1016/j.pnpbp.2004.12.009.

17. Epstein CJ. Down syndrome (Trisomy 21). In: Scriver CR, Beaudet AL, Sly WS, Valle D, editors. The Metabolic and Molecular Basis of Inherited disease. New York: McGraw-Hill; 1995;749-94.

18. Roizen NJ. Down syndrome: progress in research. Ment Retard Dev Disabil Res Rev. 2001;7:38-44, doi: 10.1002/1098-2779(200102)7:1<38::AIDMRDD1006>3.0.CO;2-C

19. Lejeune J, Gautier M, Turpin R. Study of somatic chromosomes from 9 mongoloid children. C R Hebd Seances Acad Sci. 1959;248:1721-2.

20. Nikolaienko O, Nguyen C, Crinc LS, Cios KJ, Gardiner K. Human chromosome 21/Down syndrome gene function and pathway database. Gene. 2005;364:90-8, doi: 10.1016/j.gene.2005.07.019.

21. Sérégaza Z, Roubertoux PL, Jamon M, Soumireu-Mourat B. Mouse Models of Cognitive Disorders in Trisomy 21: A Review. Behav Genet. 2006;36:387-404, doi: 10.1007/s10519-006-9056-9.

22. Escorihuela RM, Fernández-Teruel A, Vallina IF, Baamonde C, Lumbreras MA, Dierssen M, et al. A behavioral assessment of Ts65Dn mice: a putative Down syndrome model. Neurosci Lett. 1995;199:143-6, doi: 10.1016/0304-3940(95)12052-6.

23. Escorihuela RM, Vallina IF, Martínez-Cué C, Baamonde C, Dierssen M, Tobeña A, et al. Impaired short- and long-term memory in Ts65Dn mice, a model for Down syndrome. Neurosci Lett. 1998;247:171-4, doi: 10.1016/S0304-3940(98)00317-6.

24. Reeves RH, Irving NG, Moran TH, Wohn A, Kitt C, Sisodia SS, et al. A mouse model for Down syndrome exhibits learning and behaviour deficits. Nat Genet. 1995,11:177-84.

25. Sago H, Carlson EJ, Smith DJ, Rubin EM, Crnic LS, Huang TT, et al. Genetic dissection of region associated with behavioral abnormalities in mouse models for Down syndrome. Pediatr Res. 2000;48:606-13, doi: 10. 1203/00006450-200011000-00009.

26. Sago H, Carlson EJ, Smith DJ, Kilbridge J, Rubin EM, Mobley WC, et al. Ts1Cje, a partial trisomy 16 mouse model for Down syndrome, exhibits learning and behavioral abnormalities. Proc Natl Acad Sci USA. 1998; 95:6256-61, doi: 10.1073/pnas.95.11.6256.

27. Siarey RJ, Villar AJ, Epstein CJ, Galdzicki Z. Abnormal synaptic plasticity in the Ts1Cje segmental trisomy 16 mouse model of Down syndrome. Neuropharmacology. 2005;49:122-8, doi: 10.1016/j.neuropharm. 2005.02.012.

28. Belichenko PV, Kleschevnikov AM, Salehi A, Epstein CJ, Mobley WC. Synaptic and cognitive abnormalities in mouse models of Down syndrome: exploring genotype-phenotype relationships. J Comp Neurol. 2007;504:329-45, doi: 10.1002/cne.21433.

29. Belichenko NP, Belichenko PV, Kleschevnikov AM, Salehi A, Reeves $\mathrm{RH}$, Mobley WC. The "Down Syndrome Critical Region" Is Sufficient in the Mouse Model to Confer Behavioral, Neurophysiological, and Synaptic Phenotypes Characteristic of Down Syndrome. J Neurosci. 2009;29:5938-48, doi: 10.1523/JNEUROSCI.1547-09.2009.

30. Dierssen M, Herault Y, Estivill X. Aneuploidy: from a physiological mechanism of variance to Down Syndrome. Physiol Rev. 2009;89:887920, doi: 10.1152/physrev.00032.2007.

31. Conrad DF, Andrews TD, Carter NP, Hurles ME, Pritchard JK. A highresolution survey of deletion polymorphism in the human genome. Nat Genet. 2006;38:75-81, doi: 10.1038/ng1697.

32. Rehen SK, Yung YC, McCreight MP, Kaushal D, Yang AH, Almeida $\mathrm{BSV}$, et al. Constitutional Aneuploidy in the normal human brain J Neurosci. 2005;25:2176-80.

33. Oostra BA, Chiurazzi P. The fragile $X$ gene and its function. Clin Genet. 2001;60:399-408, doi: 10.1034/j.1399-0004.2001.600601.x.

34. Bakker CE, Oostra BA. Understanding fragile $X$ syndrome: insights from animal models. Cytogenet Genome Res. 2003;100:111-23, doi: 10. $1159 / 000072845$.

35. Bakker CE, Verheij C, Willemsen R, van der Helm R, Oerlemans F, Vermey, et al. Fmr1 knockout mice: a model to study fragile $\mathrm{X}$ mental retardation. Cell. 1994;78:23-33.

36. Curia G, Papouin T, Séguéla P, Avoli M. Downregulation of tonic GABAergic inhibition in a mouse model of fragile $X$ syndrome. Cereb Cortex. 2009;19:1515-20, doi: 10.1093/cercor/bhn159.

37. Dunn HG, MacLeod PM. Rett syndrome: review of biological abnormalities. Can J Neurol Sci. 2001;28:16-29. 
38. Amir RE, Van den Veyver IB, Wan M, Tran CQ, Francke U, Zoghbi HY. Rett syndrome is caused by mutations in X-linked MECP2, encoding methyl-CpG-binding protein 2. Nat. Genet. 1999;23:185-8, doi: 10.1038/ 13810 .

39. Guy J, Hendrich B, Holmes M, Martin JE, Bird A. A mouse Mecp2-null mutation causes neurological symptoms that mimic Rett syndrome. Nat Genet. 2001;27:322-6, doi: 10.1038/85899.

40. Chen RZ, Akbarian S, Tudor M, Jaenisch R. Deficiency of methyl-CpG binding protein-2 in CNS neurons results in a Rett-like phenotype in mice. Nat Genet. 2001;27:327-31, doi: 10.1038/85906.

41. Shahbazian M, Young J, Yuva-Paylor L, Spencer C, Antalffy B, Noebels $\mathrm{J}$, et al. Mice with truncated $\mathrm{MeCP} 2$ recapitulate many Rett syndrome features and display hyperacetylation of histone H3. Neuron. 2002;35:243-54, doi: 10.1016/S0896-6273(02)00768-7.

42. LaSalle JM, Yasui DH. Evolving role of MeCP2 in Rett syndrome and autism. Epigenomics. 2009;1:119-30, doi: 10.2217/epi.09.13.

43. Champion MP. An approach to the diagnosis of inherited metabolic disease. Arch Dis Child Educ Pract Ed. 2010;95:40, doi: 10.1136/adc. 2008.151183

44. Garcia-Cazorla A, Wolf NI, Serrano M, Moog U, Pérez-Dueñas B, Póo P, et al. Mental retardation and inborn errors of metabolism. J Inherit Metal Dis. 2009;32:597-608.

45. de Carvalho TM, dos Santos HP, dos Santos IC, Vargas PR, Pedrosa J. Newborn screening: a national public health programme in Brazil. J Inherit Metab Dis. 2007;30:615, doi: 10.1007/s10545-007-0650-7.

46. Borrajo GJC. Newborn screening in Latin America at the beginning of the 21st century. J Inherit Metab Dis. 2007;30:466-81, doi: 10.1007/ s10545-007-0669-9.

47. Monteiro LTB, Cândido LMB. Phenylketonuria in Brazil: evolution and cases. Rev Nutr. 2006;19:381-7, doi: 10.1590/S1415-52732006000300009.

48. Loupe PS, Bredemeier JD, Schroeder SR, Tessel RE. Dopamine reuptake inhibitor GBR-12909 induction of aberrant behaviors in animal models of dopamine dysfunction. Int J Dev Neurosci. 2002;20:323-33, doi: 10.1016/S0736-5748(02)00054-0.

49. Hooper M, Hardy K, Handyside A, Hunter S, Monk M. HPRT-deficient (Lesch-Nyhan) mouse embryos derived from germline colonization by cultured cells. Nature. 1987;326:292-5, doi: 10.1038/326292a0.

50. Egami K, Yitta S, Kasim S, Lewers JC, Roberts RC, Lehar M, et al. Basal ganglia dopamine loss due to defect in purine recycling. Neurobiol Dis. 2007;26:396-407, doi: 10.1016/j.nbd.2007.01.010.

51. Jinnah HA. Lesch-Nyhan disease: from mechanism to model and back again. Dis Model Mech. 2009;2:116-21, doi: 10.1242/dmm.002543.

52. Breese GR, Criswell HE, Duncan DE, Mueller RA. A dopamine deficiency model of Lesch-Nyhan disease-the neonatal-6-OHDAlesioned rat Brain Res Bull. 1990;25:477-84.

53. Breese GR, Knapp DJ, Criswell HE, Moy SS, Papadeas ST, Blake BL. The neonate 6-hydroxydopamine lesioned rat: a model for clinical neuroscience and neurobiological principles. Brain Res. Rev. 2004;48:57-73, doi: 10.1016/j.brainresrev.2004.08.004.

54. Fisher $\mathrm{MH}$, Welker $\mathrm{C}$, Waisman $\mathrm{H}$. Generalised growth retardation in rats induced by prenatal exposure to methylazoxymethanol acetate. Teratol. 1972;6:223-32, doi: 10.1002/tera.1420050212.

55. Johnston MV, Coyle JT. Histological and neurochemical effects of fetal treatment with methylazoxymethanol on rat neocortex in adulthood Brain Res. 1979;170:135-55.

56. Vorhees CV, Fernandez K, Dumas RM, Haddad RK. Pervasive hyperactivity and long-term learning impairments in rats with induced micrencephaly from prenatal exposure to methylazoxymethanol. Developmental Brain Res. 1984;1:1-10, doi: 10.1016/0165-3806(84)90134-2.

57. Archer T, Hard E, Hansen S. Animal models of mental retardation. In: Boulton A, Baker G, Martin-Iverson M, editors. Animal Models of Psychiatry II. Neuromethods. CliftonNJ:Humana Press;1991; pp. 273314.

58. Schroeder SR. Mental retardation and developmental disabilities influenced by environmental neurotoxic insults. Environ Health Perspect. 2000;108Suppl.3:395-9, doi: 10.2307/3454526.

59. Berkowitz GS, Wetmur JG, Birman-Deych E, Obel J, Lapinski RH, Godbold JH, et al. In utero pesticide exposure, maternal paraoxonase activity, and head circumference. Environ Health Perspect. 2004;112:38891, doi: 10.1289/ehp.6414.

60. Chiodo LM, Jacobson SW, Jacobson JL. Neurodevelopmental effects of postnatal lead exposure at very low levels. Neurotoxicol Teratol. 2004;26:359-71, doi: 10.1016/j.ntt.2004.01.010.

61. Eskenazi B, Harley K, Bradman A, Weltzien E, Jewell NP, Barr DB, et al. Association of in utero organophosphate pesticide exposure and fetal growth and length of gestation in an agricultural population. Environ Health Perspect. 2004;112:1116-24, doi: 10.1289/ehp.6789.

62. Lanphear BP. Congressional Briefing in the American Association on Mental Retardation's Environmental Health Initiative, Learning Disabilities Association of America's Healthy Children Project Collaborative on Health and the Environment's Learning and Developmental Disabilities Initiative May 10, 2005. Available from: http:/ /:www.aamr.org
63. Rice DC. Animal Models of Cognitive Impairment Produced by Developmental Lead Exposure. In: Levin ED, Buccafusco JJ, editors. Animal Models of Cognitive Impairment. CRC Press Taylor \& Francis Group, LLC. Boca Raton, FL: 2006.

64. Jacobson JL, Jacobson SW. Prenatal exposure to polychlorinated biphenyls and attention at school age. J Pediatrics. 2003;143:780-8, doi: 10.1067/S0022-3476(03)00577-8.

65. Stewart P, Fitzgerald S, Reihman J, Gump B, Lonky E, Darvill T, et al. Prenatal PCB exposure, the corpus callosum, and response inhibition. Environmental Health Perspect. 2003;111:1670-7, doi: 10.1289/ehp. 6173.

66. Buxton D, Finlayson J. Experimental infection of pregnant sheep with Toxoplasma gondii: pathological and immunological observations on the placenta and foetus. J Comp Pathol. 1986;96:319-33, doi: 10.1016/00219975(86)90052-6.

67. Dubey JP, Shen SK. Rat model of congenital toxoplasmosis. Infect. Immun. 1991;59:3301-2.

68. Roberts CW, Alexander J. Studies on a murine model of congenital toxoplasmosis: vertical disease transmission only occurs in BALB/c mice infected for the first time during pregnancy. Parasitology. 1992;104:19-23, doi: 10.1017/S0031182000060753.

69. Zenner L., Estaquier J, Darcy F, Maes P, Capron A, Cesbron-Delauw MF. Protective immunity in the rat model of congenital toxoplasmosis and the potential of excreted-secreted antigens as vaccine components. Parasite Immunol. 1999;21:261-72, doi: 10.1046/j.1365-3024.1999. 00229.x.

70. Haumont M, Delhaye L, Garcia L, Jurado M, Mazzu P, Daminet V, et al. Protective Immunity against Congenital Toxoplasmosis with recombinant SAG1 Protein in a Guinea Pig Model. Infection and Immunity. 2000;68:4948-53, doi: 10.1128/IAI.68.9.4948-4953.2000.

71. Wong SY, Remington JS. Toxoplasmosis in pregnancy. Clin Infect Dis. 1994;18:853-61, doi: 10.1093/clinids/18.6.853.

72. Demmler GJ. Congenital cytomegalovirus infections. Semin Pediatr Infect Dis. 1994;5:52-5.

73. De Paschale M, Agrappi C, Manco MT, Paganini A, Clerici P. Incidence and risk of cytomegalovirus infection during pregnancy in an urban area of northern Italy. Infect Dis Obstet Gynecol. 2009;2009:206505, doi: $10.1155 / 2009 / 206505$

74. Powers C, Früh K. Rhesus CMV: an emerging animal model for human CMV. Med Microbiol Immunol. 2008;197:109-15, doi: 10.1007/s00430007-0073-y.

75. Alexander D. Prevention of mental retardation: four decades of research. Ment Ret Dev Dis Res Rev. 1998;4:50-8, doi: 10.1002/ (SICI)1098-2779(1998)4:1<50::AID-MRDD8>3.0.CO;2-0.

76. Ministérioda Sadeú. Campanha Nacional de Vacinação contra a Rubéola 2008; Available from: http://portal.saude.gov.br

77. Webster WS. Teratogen Update: Congenital Rubella. Teratology. 1998;58:13-23, doi: 10.1002/(SICI)1096-9926(199807)58:1<13::AIDTERA5 $>3.0 . \mathrm{CO} ; 2-2$

78. Chudley AE, Kilgour AR, Cranston M, Edwards M. Challenges of diagnosis in fetal alcohol syndrome and fetal alcohol spectrum disorder in the adult. Am J Med Genet C Semin Med Genet. 2007;145C:261-72 doi: 10.1002/ajmg.c.30140.

79. Kelly SJ, Goodlett CR, Hannigan JH. Animal models of fetal alcohol spectrum disorders: impact of the social environment. Dev Disabil Res Rev. 2009;15:200-208, doi: 10.1002/ddrr.69.

80. Sulik KK, Johnston MC, Webb MA. Fetal alcohol syndrome: embryogenesis in a mouse model. Science. 1981;214:936-38, doi: 10.1126/ science.6795717.

81. Sulik KK, Lauder JM, Dehart DB. Brain malformations in prenatal mide following acute maternal ethanol administration. Int J Dev Neurosci. 1984;2:203-14, doi: 10.1016/0736-5748(84)90014-5.

82. Cook CS, Nowotny AZ, Sulikk KK. Fetal alcohol syndrome: eye malformations in a mouse model. Arch Ophtalmol. 1987;105:1576-81.

83. Webster WS, Walsh DA, McEwen SE, Lipson AH. Some teratogenic properties of ethanol and acethaldehyde in implications for the study of the fetal alcohol syndrome teratology. Teratology. 1983;27:231-43, doi: 10.1002/tera.1420270211.

84. Trier E, Thomas AG. Feeding the disabled child. Nutrition. 1998;14:8015, doi: 10.1016/S0899-9007(98)00088-4.

85. Blossner M, de Onis M. Malnutrition: quantifying the health impact at national and local levels. Environmental Burden of Disease Series. Geneva, Switzerland: World Health Organization; 2005.

86. Stratton RJ, Green CJ, Elia M. Disease-related Malnutrition: an Evidence-based Approach to Treatment. Cambridge, MA: CAB International; 2003.

87. Pollitt E. Developmental sequel from early nutritional deficiencies: conclusive and probability judgements. J Nutr. 2000;130(2S Suppl):350S-3S.

88. Volpe JJ. Perinatal brain injury: from pathogenesis to neuroprotection. Ment Retard Dev Disabil Res Rev. 2001;7:56-64, doi: 10.1002/10982779(200102)7:1<56::AID-MRDD1008>3.0.CO;2-A. 
89. Roohey T, Raju TN, Moustogiannis AN. Animal models for the study of perinatal hypoxic-ischemic encephalopathy: a critical analysis. Early Hum Dev. 1997;47:115-46, doi: 10.1016/S0378-3782(96)01773-2.

90. Wagner BP, Nedelcu J, Martin E. Delayed postischemic hypothermia improves long-term behavioral outcome after cerebral hypoxiaischemia in neonatal rats. Pediatr Res. 2002;51:354-60, doi: 10.1203/ 00006450-200203000-00015.

91. Lee JH, Lee YK, Ishikawa M, Koga K, Fukunaga M, Miyakoda G, et al. Cilostazol reduces brain lesion induced by focal cerebral ischemia in rats-an MRI study. Brain Res. 2003;994:91-8, doi: 10.1016/j.brainres. 2003.09.021.

92. Wang Y, Cheung PT, Shen GX, Wu EX, Cao G, Bart I, et al. Hypoxicischemic brain injury in the neonatal rat model: relationship between lesion size at early MR imaging and irreversible infarction. AJNR Am J Neuroradiol. 2006;27:51-4.

93. Holmes GL, Khazipov R, Ben-Ari Y. New concepts in neonatal seizures. Neuroreport. 2002;13:A3-A8, doi: 10.1097/00001756-200201210-00002.

94. Simon NP. Long-term neurodevelopmental outcome of asphyxiated newborns. Clin Perinatol. 1999;26:767-78.

95. Yager RGY. Pathophysiology of perinatal brain damage. Brain Res Rev. 1999;30:107-34, doi: 10.1016/S0165-0173(99)00009-0.

96. Rice JE, Vannucci RC, Brierley JB. The influence of immaturity on hypoxic-ischemic brain damage in the rat. Ann Neurol. 1981;9:131-41, doi: 10.1002 /ana.410090206.

97. Nuñez JL, Alt JJ, McCarthy MM. A new model for prenatal brain damage. I. GABAA receptor activation induces cell death in developing rat hippocampus. Exp Neurol. 2003;181:258-69, doi: 10.1016/S00144886(03)00053-0.

98. Nuñez JL, Alt JJ, McCarthy MM. A novel model for prenatal brain damage II. Long-term deficits in hippocampal cell number and hippocampaldependent behavior following neonatal GABAA receptor activation. Exp Neurol. 2003;181:270-80, doi: 10.1016/S0014-4886(03)00051-7.

99. Bittigau P, Sifringer M, Felderhoff-Mueser U, Hansen HH, Ikonomidou C. Neuropathological and biochemical features of traumatic injury in the developing brain. Neurotox Res. 2003;5:475-490, doi: 10.1007/ BF03033158.

100. Bittigau P, Pohl D, Sifringer M, Shimizu H, Ikeda M, Ishimaru M, et al. Modeling pediatric head trauma: mechanisms of degeneration and potential strategies for neuroprotection. Restor Neurol Neurosci. 1998;13:11-23.

101. Garzon E. Estado de Mal epiléptico. J Epilepsy Clin Neurophysiol. 2008;14Suppl 2:7-11.

102. Meldrum BS, Horton RW. Physiology of status epilepticus in primates. Arch Neurol. 1973;28:1-9.

103. Nevander G, Ingvar M, Auer R, Siesjo BK. Status epilepticus in welloxygenated rats causes neuronal necrosis. Ann Neurol. 1985;18:281-90, doi: 10.1002/ana.410180303.

104. Santos NF, Marques RH, Correia L, Sinigaglia-Coimbra R, Calderazzo L, Sanabria ER, et al. Multiple pilocarpine-induced status epilepticus in developing rats: a long-term behavioral and electrophysiological study. Epilepsia. 2000;41Suppl 6:S57-63, doi: 10.1111/j.1528-1157.2000. tb01558.x.
105. Milgram NW, Isen DA, Mandel D, Palantzas H, Pepkowski MJ. Deficits in spontaneous behavior and cognitive functions following systemic administration of kainic acid. Neurotoxicol. 1988;9:611-24.

106. Wolvetang EW, Bradfield OM, Tymms M, Zavarsek S, Hatzistavrou T, Kola I, et al. The chromosome 21 transcription factor ETS2 transactivates the beta-APP promoter: implications for Down syndrome. Biochim Biophys Acta. 2003;1628:105-10.

107. Netzer WJ, Powell C, Nong Y, Blundell J, Wong L, Duff K, et al. Lowering beta-amyloid levels rescues learning and memory in a Down syndrome mouse model. PLoS One. 2010;5:e10943, doi: 10.1371/journal. pone. 0010943

108. Akeson EC, Lamber JP, Narayanswami S, Gardiner $\mathrm{K}$, Bechtel LJ Davisson MT. Ts65Dn-localization of the translocation breakpoint and trisomic gene content in a mouse model for Down syndrome. Cytogenet Cell Genet. 2001;93:270-6, doi: 10.1159/000056997.

109. Granholm AC, Sanders LA, Crnic LS. Loss of cholinergic phenotype in basal forebrain coincides with cognitive decline in a mouse model of Down's syndrome. Exp Neurol. 2000;161:647-63, doi: 10.1006/exnr. 1999.7289

110. Holtzman DM, Santucci D, Kilbridge J, Chua-Couzens J, Fontana DJ, Daniels SE, et al. Developmental abnormalities and age-related neurodegeneration in a mouse model of Down syndrome. Proc Natl Acad Sci USA. 1996;93:13333-8, doi: 10.1073/pnas.93.23.13333.

111. Glenner GG, Wong CW. Alzheimer's disease: initial report of the purification and characterization of a novel cerebrovascular amyloid protein. Biochem Biophys Res Commn. 1984;120:885, doi: 10.1016/ S0006-291X(84)80190-4.

112. Goate A, Chartier-Harlin MC, Mullan M, Brown J, Crawford F, Fidani $\mathrm{L}$, et al. Segregation of a missense mutation in the amyloid precursor protein gene with familial Alzheimer's disease. Nature. 1991;349:704-6, doi: $10.1038 / 349704 \mathrm{a} 0$.

113. Hsiao K, Chapman P, Nilsen S, Eckman C, Harigaya Y, Younkin S, et al. Correlative memory deficits, Abeta elevation, and amyloid plaques in transgenic mice. Science. 1996;274:99, doi: 10.1126/science.274.5284.99.

114. Morris RG, Garrud P, Rawlins JN, O'Keefe J. Place navigation impaired in rats with hippocampal lesions. Nature. 1982;297:681, doi: 10.1038/ $297681 \mathrm{a} 0$.

115. Ohno M, Sametsky EA, Younkin LH, Oakley H, Younkin SG, Citron M, et al. BACE1 deficiency rescues memory deficits and cholinergic dysfunction in a mouse model of Alzheimer's disease. Neuron. 2004;41:27-33, doi: 10.1016/S0896-6273(03)00810-9.

116. Terry AV Jr, Buccafusco JJ. The cholinergic hypothesis of age and Alzheimer's disease-related cognitive deficits: recent challenges and their implications for novel drug development. J Pharmacol Exp Ther. 2003;306:821-7, doi: 10.1124/jpet.102.041616.

117. Zhang L. Cholinergic Receptors Knockout Mice.Chapter 11. In: Levin ED, Buccafusco JJ, editors. Animal Models of Cognitive Impairment. Boca Raton: CRC Press; 2006.

118. Volpicelli-Daley LA, Duysen EG, Lockridge O, Levey AI. Altered hippocampal muscarinic receptors in acetylcholinesterase-deficient mice. Ann Neurol. 2003;53:788-96, doi: 10.1002/ana.10589. 